\title{
A young woman with a divided left atrium
}

\author{
Nilson Lopez-Ruiz, ${ }^{1}$ Rafael Lince, ${ }^{2}$ Beatriz Ramirez ${ }^{2}$
}

${ }^{1}$ Division of Cardiology, Hospital Pablo Tobon Uribe, Medellin, Antioquia, Colombia ${ }^{2}$ Clinica CardioVID, Division of Paediatric Cardiology, Medellin, Antioquia, Colombia

\section{Correspondence to} Dr Nilson Lopez-Ruiz, nlopez@hptu.org.co

\section{DESCRIPTION}

A 19-year-old woman was sent for a twodimensional transthoracic echocardiography because of dyspnea on mild exertion of recent onset. An echocardiography revealed a membrane dividing the left atrium (LA) into a posterosuperior chamber (SC) and an anteroinferior chamber (IC) (figure 1A, video 1). However, no Doppler colour flow acceleration (figure $1 \mathrm{~B}$, video 2 ) or pressure gradient was noted. LA appendage was included in IC (figure 1C). The right heart and pulmonary artery pressure were both normal. A threedimensional echocardiography showed the membrane in greater detail and revealed the orifice through which the blood flowed from SC to IC (video 3). Unrestrictive cor triatriatum was diagnosed and a cardiac MRI ruled out associated congenital heart defects (figure 1D). Finally, an exercise stress test was normal, so further management was expectant. Three years later, the patient remains asymptomatic.

In classic cor triatriatum, a fibromuscular diaphragm with fenestrations divides LA into SC

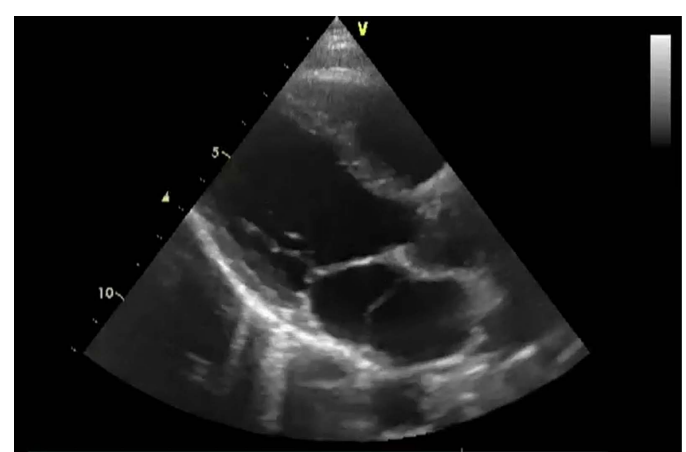

Video 1 Two-dimensional echocardiography (long paraesternal view) showing a membrane inside the left atrium.

(receiving pulmonary venous flow) and IC (true LA, containing the left atrial appendage and mitral orifice). ${ }^{1}$ The insertion of the diaphragm proximal to the left atrial appendage is the feature that

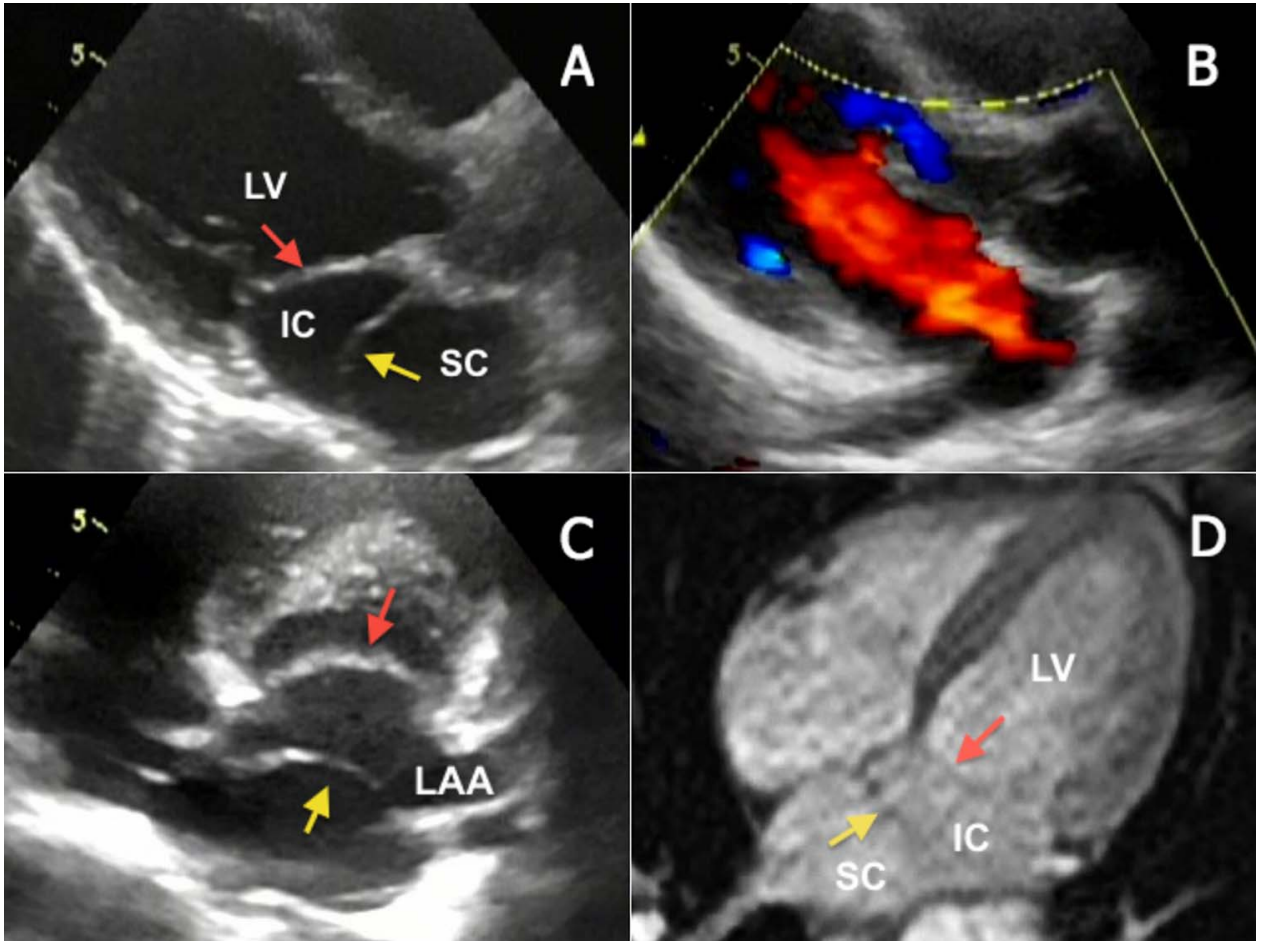

Figure 1 (A) Transthoracic echocardiography showing a membrane (yellow arrow) dividing the left atrium into a posterosuperior chamber and anteroinferior chamber, the latter being the true left atrium that communicates with the mitral valve (red arrow). (B) The membrane was not restrictive as no acceleration was noted on Doppler colour flow. (C) Membrane insertion proximal to the left atrial appendage (arrows as previously described). (D) Cardiac MRI confirmed the echocardiographic findings and the diagnosis of classical cor triatriatum (arrows as previously described). 


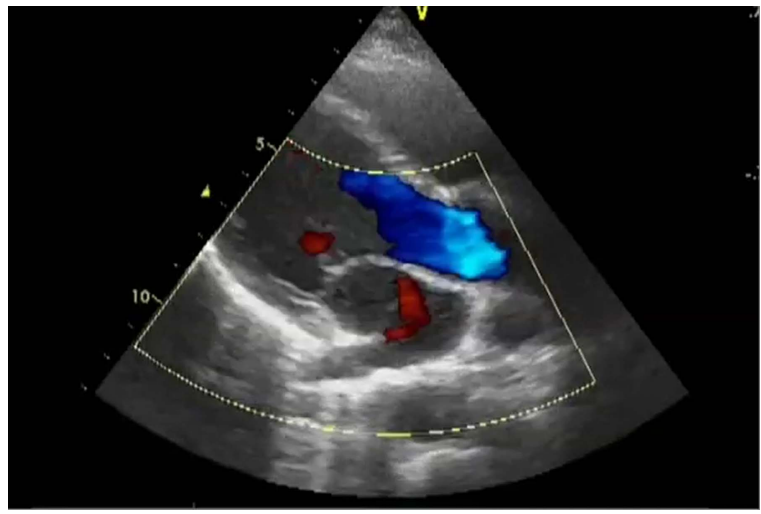

Video 2 Doppler colour flow echocardiography displaying normal blood flow from pulmonary veins through the membrane.

distinguishes cor triatriatum from the supravalvular stenosing mitral ring. ${ }^{2}$ Age and symptoms at the time of diagnosis depend on the degree of obstruction to pulmonary venous

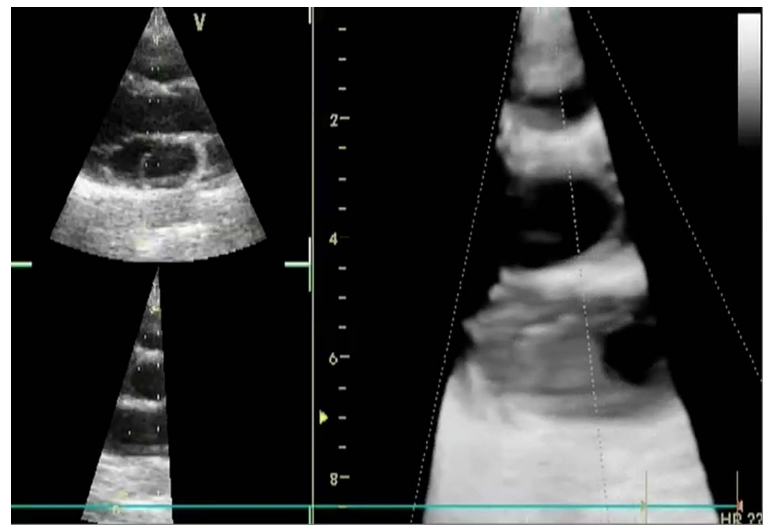

Video 3 Three-dimensional echocardiography demonstrating the diaphragm with an orifice viewed from the posterosuperior chamber. return and associated lesions. ${ }^{2}$ However, older adults with a non-obstructive cor triatriatum may present with mitral regurgitation or atrial fibrillation. ${ }^{3}$ Treatment of asymptomatic adults is controversial and may be indicated only in those who participate in vigorous exercise, or in women considering pregnancy. $^{2}$

\section{Learning points}

- Cor triatriatum in adults is an uncommon, incidental finding on an echocardiography and is usually non-restrictive.

- A membrane dividing the left atrium is seen in cor triatriatum and supravalvular mitral ring. However, the position of the membrane relative to the left atrial appendage is the distinguishing feature of the cor triatriatum.

- When the patient is asymptomatic, surgical or percutaneous intervention is reserved for those involved in vigorous athletic activities, or in women considering pregnancy.

Contributors NL-R, RL and BR were equally involved in the planning, execution and reporting of the work.

Competing interests None.

Patient consent Obtained.

Provenance and peer review Not commissioned; externally peer reviewed.

\section{REFERENCES}

1 Herlong JR, Jaggers JJ, Ungerleider RM. Congenital Heart Surgery Nomenclature and Database Project: pulmonary venous anomalies. Ann Thorac Surg 2000;69(4 Suppl): S56-69.

2 Dipchand A, Freedom R, Yoo S. The divided left atrium (cor triatriatum). In: Freedom RM, Yoo SJ, Mikailian H, Williams WG. eds The natural and modified natural history of congenital heart disease. New York: Futura: 2004:295-8.

3 Vallakati A, Nerella N, Chandra P, et al. Incidental diagnosis of cor triatriatum in 2 elderly patients. J Am Coll Cardiol 2012;59:e43.

Copyright 2013 BMJ Publishing Group. All rights reserved. For permission to reuse any of this content visit

http://group.bmj.com/group/rights-licensing/permissions.

BMJ Case Report Fellows may re-use this article for personal use and teaching without any further permission.

Become a Fellow of BMJ Case Reports today and you can:

- Submit as many cases as you like

- Enjoy fast sympathetic peer review and rapid publication of accepted articles

- Access all the published articles

- Re-use any of the published material for personal use and teaching without further permission

For information on Institutional Fellowships contact consortiasales@bmjgroup.com

Visit casereports.bmj.com for more articles like this and to become a Fellow 